\title{
IMPLEMENTASI KEBIJAKAN SEKOLAH TENTANG POIN PELANGGARAN TATA TERTIB SISWA DALAM MEMBENTUK PERILAKU SISWA YANG BERKARAKTER DI SMA NEGERI 7 KEDIRI
}

\author{
Churiyatul Qisthi Rodhiyah \\ Annisa Rahmadiah Ali \\ Mufarrihul Hazin \\ State Colleges of Islamic Studies (STAIN) Kediri, Indonesia
}

\begin{abstract}
Schools play a very important role in establishing and shaping the behavior of the younger generations. This research aims to: 1). Describing the school policy implementation model on the violation points of code of conduct of Students 2). Describing barriers in implementing school policies on the students ' Code of conduct violations. 3). Describing efforts to overcome barriers in implementing school policies on the students ' Code of conduct violations. The method used in this research is through a qualitative approach to the case study type. The data analysis techniques in this research use the interactive models of Miles and Huberman, namely the condensation of data, display data, and draw conclusions. Validity of data using triangaluation and peer discussions. The results of this study show: 1). Violations of the order of students using violation points, 2). Barriers to the implementation of student order include the physical environmental barrier of the school and student consciousness. 3). Efforts to overcome the barriers to implementation of the student order is done by the way the headmaster conducts coaching teachers, employees, and all elements in the school.
\end{abstract}

Keyword: Character education, policy, violation points.

\begin{abstract}
Abstrak: Sekolah memiliki peran yang sangat penting dalam membangun dan membentuk perilaku para generasi muda. Penelitian ini bertujuan untuk: 1). mendeskripsikan model pelaksanaan kebijakan sekolah tentang poin pelanggaran tata tertib siswa 2). mendeskripsikan hambatan-hambatan dalam pelaksanaan kebijakan sekolah tentang poin pelanggaran tata tertib siswa. 3). mendeskripsikan upaya-upaya mengatasi hambatan dalam melaksanakan kebijakan sekolah tentang poin pelanggaran tata tertib siswa. Metode yang digunakan dalam penelitian ini adalah melalui pendekatan kualitatif dengan jenis study kasus. Teknik analisis data dalam penelitian ini menggunakan model interaktif Miles dan Huberman, yaitu kondensasi data, display data, dan menarik kesimpulan. Keabsahan data menggunakan triangaluasi dan diskusi teman sejawat. Hasil penelitian ini menunjukkan: 1). Pelanggaran tata tertib siswa dengan menggunakan poin pelanggaran, 2). Hambatan-hambatan dalam pelaksanaan tata tertib siswa meliputi hambatan lingkungan fisik sekolah dan kesadaran siswa. 3). Upaya mengatasi hambatan pelaksanaan tata tertib siswa dilakukan dengan cara kepala sekolah mengadakan pembinaan guru, karyawan, dan semua elemen yang ada di sekolah.
\end{abstract}

Kata kunci: Pendidikan karakter, kebijakan, poin pelanggaran.

Sekolah merupakan suatu lembaga pendidikan yang notabennya berperan untuk membentuk perilaku, watak, kepribadian dan menimba ilmu bagi siswa sehingga terbentuklah siswa yang berkarakter dan berbudaya luhur. Disisi lain sekolah dipandang sebagai suatu masyarakat yang utuh dan bulat serta memiliki kepribadian sendiri, menjadi tempat untuk menyelenggarakan proses belajar mengajar. Selain itu, sekolah juga berperan untuk mencerdaskan kehidupan bangsa, dalam artian menumbuhkan, memotivasi dan mengembangkan nilai-nilai budaya yang mencakup etika, logika, estetika dan praktika sehingga terciptalah manusia yang utuh dan berakar pada budaya bangsa. "The moral and civic 
dimensions of personal character have been widely recognized and explored" (Baehr, 2017). Sikap dan perilaku menjunjung tinggi kemanusiaan yang adil dan beradab diwujudkan dalam perilaku saling menghormati antarwarga (Khusniati, 2012). Pendidikan karakter merupakan satu upaya untuk menangani permasalahan krisis multidimensional yang saat ini terjadi (Hasan, 2012). Pendidikan karakter dimaknai sebagai pendidikan nilai, budi pekerti, pendidikan moral, pendidikan watak yang tujuannya untuk mengembangkan kemampuan peserta didik untuk memberikan keputusan baik buruk, mewujudkan kebaikan dalam kehidupan sehari-hari dengan sepenuh hati sebagai cita-cita luhur dalam dunia pendidikan.(Ismadi, 2014). Nilai-nilai kehidupan merupakan dimensi pembentuk karakter (Wening, 2012). Menurut Heru Wibowo (2010) dalam kehidupan masyarakat yang semakin maju dan berkembang seperti sekarang ini persoalan-persoalan yang dihadapi masyarakat semakin kompleks, karena adanya perubahan-perubahan dalam berbagai kehidupan masyarakat. Pendidikan karakter penting bagi kehidupan manusia, maka peran yang dimainkan dunia pendidikan haruslah tidak sekadar menunjukkan pengetahuan moral, tetapi juga mencintai dan mau melakukan tidakan moral (Ajat Sudrajat, 2011). Kondisi krisis moral pascareformasi menunjukkan capaian kompetensi moral yang diproses melalui bangku persekolahan belum menghasilkan keluaran pengembangan kecerdasan moral peserta didik (Deny Setiawan, 2013). Dalam membentuk perilaku yang berkarakter, SMAN 7 Kediri membuat kebijakan tentang peraturan dan tata tertib yang berkaitan dengan pembentukan perilaku siswa sehingga pengaruh negatif dari luar dapat diminimalisir dan juga dihindari. Dengan adanya peraturan dan tata tertib sekolah yang baik dan disepakati oleh semua pihak, yaitu guru, karyawan, siswa, orang tua siswa, komite sekolah, maka diharapkan kegiatan pembelajaran di sekolah dapat berjalan dengan efektif dan efisien. Pendidikan karakter merupakan proses pemberian tuntunan peserta atau anak didik agar menjadi manusia Indonesia seutuhnya yang berkarakter dalam dimensi hati, pikir, raga, serta rasa dan karsa (Jaya, 2012). Miller menyatakan "Character refers to those aspects of personality that are learned through experience, throughtraining,orthroughasoci alizationprocess" (Miller, Kraus, \& Veltkamp, 2008). "Misunderstandings, disagreements, and problems in reforming higher education today are often due to unfortunate misuses or confusions on meanings of essential concepts" (Thelin, 2013). Sebagaimana yang dikemukakan oleh Lee bahwa "Character Education practice in our elementary schools, and suggests effective strategies for Character Education that are both practical and suitable" (Lee, 2001).

Gilead menyatakan "Following the rise of virtue and character education, educational philosophers have recently given much attention to questions relating to virtue and the good. " (Gilead, 2011). Dalam hal ini menurut Edward (1980), terdapat empat aspek dalam pengimplementasian suatu kebijakan yakni, dari segi komunikasi, sumber daya, disposisi, dan struktur birokrasi. Namun titik tumpu terberat kami dalam penelian ini adalah pada segi disposisi, yaitu pada poin pelanggaran tata tertib siswa dalam membentuk perilaku siswa yang berkarakter. "Demonstrate the benefit of educational professionals being knowledgeable of the definitions and circumstances related to character education and bullying prevention," (Freeman, 2014). Hal ini karena peneliti merasa poin pelanggaran tata tertib siswa sangat menentukan perilaku siswa yang berkarakter dalam mengimplementasikan kebijakan sekolah tentang poin pelanggaran tata tertib siswa.

Sebagaimana disebutkan diatas dalam UU Sisdiknas No.20 Tahun 2003 pasal 1 ayat 1 didalamnya terkandung harapanharapan yang sangat mulia yaitu terciptalah siswa yang memiliki kekuatan spiritual keagamaan, pengendalian diri, kepribadian yang baik serta akhlak yang mulia, namun melihat realita yang terjadi, dalam pelaksanaannya di SMPN 7 Kediri masih banyak penyimpangan- 
penyimpangan perilaku yang dilakukan oleh siswa. Hal ini ditunjukkan dengan masih banyaknya siswa yang berperilaku tidak disiplin dan tidak bertanggung jawab, baik diluar sekolah maupun didalam lingkungan sekolah seperti siswa datang terlambat, siswa tidak menggunakan atribut lengkap, tidak mengerjakan tugas dari guru, memakai baju tidak sesuai dengan ketentuan sekolah, tidak sopan kepada bapak ibu guru dan lain sebagainya.

Dengan menegakkan peraturan dan tata tertib sekolah, maka diharapkan akan terbentuk siswa yang disiplin dan bertanggung jawab, sehingga masalah pelanggaran-pelanggaran moral yang sering terjadi seperti datang terlambat, dikelas ramai, dan lain sebagainya dapat ditekan seminimal mungkin. Peraturan hanya akan abadi kalau kearifan lokal terimplementasikan dalam kehidupan konkret sehari-hari sehingga mampu merespons dan menjawab arus zaman yang telah berubah (Fajarini, 2014). Individu yang perilakunya sesuai dengan kaidah moral disebut dengan berkarakter mulia (Ani, 2014). Banyak penelitian menunjukkan lingkungan pendidikan memberikan pengaruh besar dalam pendidikan karakter (Mulvey, 1984). Untuk mewujudkan semua itu, perlu adanya formula khusus agar tata tertib dapat dijalankan secara efektif dan efisien., dengan peraturan tata tertib yang baik dan sudah disetujui oleh semua elemen sekolah, juga dijalankan dengan benar, diharapkan dapat menciptakan situasi dan kondisi sekolah cukup kondusif. Situasi yang kondusif dapat membantu kegiatan belajar mengajar berlangsung tenang dan aman, sehingga siswa dapat mencapai prestasi yang optimal. Kita mengetahui bahwa tiap kelompok kesatuan sosial sekecil apapun, keluarga, kelompok bermain, misalnya selalu mempunyai peraturan-peraturan tertentu, yang sedikit banyak berbeda antara yang satu dengan yang lain. Adanya peraturan-peraturan itu antara lain adalah untuk menjamin kehidupan yang tertib dan tenang, hingga, kelangsungan hidup sosial itu dapat dicapai, kewajiban anggota baru bagi kelompok sosial adalah menyesuaikan diri terhadap peraturan-peraturan tersebut. Setiap pelanggaran akan mengakibatkan gangguan bagi anggota kelompok bahkan kehidupan seluruh kelompok (Sujanto: 1996).

Demikian halnya dengan kedatangan siswa di sekolah di sekolah ia menjadi anggota baru bagi masyarakat sekolah, barulah diketahui oleh siswa bahwa dalam kesatuan sosial tersebut terdapat peraturan dan tata tertib sekolah, yang berlaku baginya, dan bila ia tidak dapat menyesuaikan ia akan menjadi pengganggu tata tertib yang berarti ia melanggar tata tertib. Peraturan tata tertib di sekolah selalu dilengkapi dengan sanksi-sanksi tertentu, yang berpuncak kepada pemberian hukuman. Pelanggaran-pelanggaran di dalam kelas dapat diberi sanksi langsung secara bertahap misalnya: diperingatkan, ditempatkan terpisah dari siswa lainnya, diberi tugas saat istirahat, dikeluarkan dari kelas (Bill Rogers dalam A.D. Rahayu Ratnaningsih: 2004).

\section{METODE}

Penilitian ini menggunakan pendekatan kualitatif deskriptif dengan jenis studi kasus. Objek penelitian yang digunakan yaitu di SMAN 7 Kediri. Teknik pengumpulan data yang digunakan yaitu melalui observasi, wawancara langsung, dan dokumentasi. Dalam wawancara langsung peneliti melibatkan WAKA Humas, Tim Tata Tertib (Tatib), guru BK, serta peserta didik.

Teknik analisis data dalam penelitian ini menggunakan model interaktif Miles dan Huberman (2012), yaitu kondensasi data, display data, dan menarik kesimpulan. Keabsahan data menggunakan triangaluasi dan diskusi teman sejawat.

Uji keabsahan data yang digunakan yaitu: uji kredibilitas (melalui triangulasi sumber dan teknik), uji transferability (melalui penyusunan hasil penelitian secara rinci, jelas, sistematis dan dapat dipercaya), uji dependability (melalui audit keseluruhan proses penelitian), dan uji confirmability (melalui publikasi hasil peneltian). 


\section{HASIL DAN PEMBAHASAN}

Hasil penelitian yang dipaparkan merupakan hasil analisis dan validasi dan sudah merupakan hasil proses kondensasi dari SMAN 7 Kediri yang menjadi objek penelitian. Hasil penelitian ini menunjukkan: 1). Pelanggaran tata tertib siswa menggunakan sistem poin pelanggaran, 2). Hambatan-hambatan dalam pelaksanaan tata tertib siswa meliputi hambatan lingkungan fisik sekolah dan kesadaran siswa. 3). Upaya mengatasi hambatan pelaksanaan tata tertib siswa dilakukan dengan cara kepala sekolah mengadakan pembinaan guru, karyawan, dan semua elemen yang ada di sekolah 4). Dampak kebijakan sekolah adalah jumlah pelanggaran yang dilakukan siswa menurun, perilaku siswa sudah mulai menunjukkan adanya perilaku yang berkarakter diantaranya, berdisiplin, menghormati norma-norma hukum yang berlaku, bertanggung jawab, bergaya hidup sehat.

Sistem poin ini sudah sejak lama diberlakukan oleh SMAN 7 Kediri, salah satu bentuk nyatanya dari sistem pelanggaran ini adalah setiap anak memiliki buku saku sendiri untuk mengetahui berapa nilai dari pelanggaran yang sudah dilakukan oleh peserta didik. Selain itu buku saku juga sebagai pengingat sudah berapa kali peserta didik melakukan pelaggaran dan berapa point yang sudah diterima oleh peserta didik dari beberapa pelanggaran yang dilakukan. Sebagaimana yang telah ditetapkan kepala sekolah SMAN 7 Kediri tahun 2016 pada pasal 18 tentang poin pelanggaran peserta didik ,Bagi peserta didik yang mendapatkan poin 5-15 biasanya dihukum dengan dengan cara menyanyikan Indonesia Raya, membersihkan Mushola dan membersihkan lapangan sekolah karena itu masih kategori poin ringan.

Sedangkan untuk kategori berat yakni poin 20-101 maka akan dilakukan tidak lanjut mulai dari dipanggil orang tuanya, mendapat scors hingga dikeluarkan dari sekolah. Dimana yang termasuk dalam kategori berat tersebut, diantaranya: membawa senjata tajam, berkelahi antar peserta diluar maupun di dalam pihak sekolah, membawa memperjualbelikan dan mengonsumsi narkoba, peserta didik putri hamil, menganiaya atau mengeroyok kepala sekolah, guru dan karyawan, peserta didik putra berpacaran hingga menghamili, mencuri barang/uang.

Hasil penelitian ini sesuai dengan Permendiknas no. 19 tahun 2007 tentang peraturan Menteri Pendidikan Nasional Republik Indonesia tentang Standar Pengelolaan Pendidikan oleh satuan Pendidikan Dasar dan Menegah adalah: Pada lampiran no.9 tentang Budaya dan lingkungan Sekolah/Madrasah bagian $d$ adalah tata tertib sekolah/madrasah ditetapkan oleh kepala sekolah/madrasah melalui rapat dewan pendidik dena mempertimbangkan masukan komite sekolah/ dan peserta didik.

Adanya penegakan tata tertib ini bertujuan agar peserta didik jera dan tidak akan melakukan kesalahan yang sama lagi. Apabila peserta didik melakukan kesalahan yang sama lagi maka dari pihak tantib akan mengirim ke kelas-kelas yang bukan kelasnya untuk menyayikan lagu kebangsaan. Hal ini sesuai dengan motto sekolah yang tercantum dalam buku saku tersebut yakni "Mewujudkan Ketertiban dengan Kesederhanaan".

Pada suatu sistem disetiap intansi maupun sekolah dalam mengeluarkan kebijakan pasti memiliki hambatanhambatan, namun dari hambatan dapat diambil makna yang belum dimiliki pada kebijakan tersebut. Faktor yang menyebabkan hambatan pelaksanaan kebijakan adalah masih kurangnya kesadaran siswa dan sarana yang dimiliki oleh sekolah tersebut. Masih ada beberapa siswa yang masih belum sadar akan ketertiban.

Selain pada kesadaran dari siswa yang kurang dari bidang administrasinya juga belum cukup memadai, hal ini diutarakan oleh narasumber yakni lbu Wiwik, beliau berkata bahwa yang menjadi kendala pada sitem point pelanggaran ini adalah administrasi baik itu administrasi daftar ulang maupun administrasi PPDB, alasannya apabila administrasi sudah bersih tidak akan lagi ada pengurangan maupun pelebihan dari siswa. Dan itu akan memepermudah staf dalam pemasukan data pada penilaian akhir. 
Keberadaan faktor sumber daya dalam rangka menjalankan kebijakan poin pelanggaran pada SMAN 7 Kediri memegang peranan sangat peting dalam keberhasilan kebijakan. Tanpa kecukupan sumber daya, apa yang direncanakan tidak akan sama dengan apa yang akhirnya diterapkan.

Menurut Edward III (1980:53) sumber daya (resources) yang dimaksud dalam implementasi kebijakan adalah pelaksana kebijakan. Agar dapat dilaksanakan dengan baik, kesiapan sumberdaya pelaksana kebijakan publik adalah hal penting untuk diperhatikan. Kesiapan sumberdaya meliputi kualitas dan kuantitas staf pelaksana, ketersediaan informasi yang memadai, kewenangan yang diberikan kepada pelaksana kebijakan serta ketersediaan sarana dan prasarana penunjang dalam pelaksanaan kebijakan.

Hasil penelitian menujukkan bahwa pihak Tantib yang beperan langsung dalam hal ini sering sekali diingatkan oleh kepala sekolah untuk memberikan pembinaan pada peserta didik yang memiliki banyak poin pelanggaran, selain itu kepala sekolah juga memberikan pembinaan pada elemen sekolah seperti satpam dan guru piket agar tidak memberikan izin pada sembarang siswa agar proses belajar mengajar tetap berjalan dengan baik.

\section{KESIMPULAN}

Berdasarkan dari hasil wawancara yang mendalam, dokumentasi dan observasi mengenai implementasi kebijakan sekolah tentang poin pelanggaran yang dilakukan di SMAN 7 Kediri dapat disimpulkan bahwa: 1). kebijakan sekolah mengenai poin pelanggaran ini sangat membantu bagi peserta didik untuk membentuk karakter. Selain salah satu visi dari sekolah tercpai yakni berperilaku sopan dan bertutur kata santun, peduli terhadap sesama dan lingkungan, menghargai budaya bangsa, hal ini semakin memperjelasan keefesienan dari kebijakan. 2). faktor-faktor yang mempengaruhi kebijakan sekolah ini adalah adanya komunikasi tindak lanjut antara tatib dan pihak wali kelas, menjadikan siswa selalu terawasi. 3). Dampak setelah ditetapkannya implementasi program pembiasaan dalam upaya pengembangan pendidikan karakter adalah kondisi sekolah yang semakin kondusif, terjadi hubungan kekerabatan antara peserta didik dengan peserta didik dan peserta didik dengan guru. Dampak terhadap lingkungan terlihat signifikan dengan pelaku (peserta didik) senantiasa mengaplikasikan program ini di rumah.

Dalam hal ini sekolah sudah memenuhi salah satu misinya yakni berbudaya yaitu, berprilaku sopan dan bertutur kata sopan, peduli terhadap sesama dan lingkungan, menghargai budaya bangsa.

Menurut pandangan Edwards (1980) informasi kebijakan pendidikan perlu disampaikan kepada pelaku kebijakan agar pelaku kebijakan dapat mengetahui, memahami apa yang menjadi isi, tujuan, arah, kelompok sasaran kebijakan agar tujuan dan sasaran kebijakan dapat dicapai sesuai dengan yang diharapkan secara jelas dan konsisten. "Character education is an eye-catching buzzword in modern educational circles" (Chen, 2013). Buchanan juga menyatakan "In the climate of contemporary culture, many design educators are uneasy discussing character and character formation as an aspect of their work. " (Buchanan, 2001). Dari penjelasan Edward tersebut sesuai dengan hasil penelitian setelah terdapat pembiasaan pada sasaran kebijakan, metode poin pelanggaran merupakan cara yang efisien untuk mengontrol pelanggaran peserta didik, karena poin pelanggaran sangat mudah dimengerti bagi kelompok sasaran kebijakan. Selain poin pelanggaran dapat mempengaruhi nilai akademik siswa, pada sistem poin pelanggaran ini juga menjadi acuan bagi wali kelas untuk kenaikan siswanya.

\section{DAFTAR RUJUKAN}

Ajat Sudrajat. (2011). Mengapa Pendidikan Karakter? Jurnal Pendidikan Karakter, 1(1), 47-58. Retrieved from https://journal.uny.ac.id/index.php/jpka /article/view/1316/1094

Ani, N. A. (2014). Pendidikan karakter untuk siswa sd dalam perspektif 
islam. Mimbar Sekolah Dasar, 1(1), 50-58. https://doi.org/10.1016/S00220248(02)02148-6

A.D.Rahayu Ratna Ningsih. (2004). Pemulihan Perilaku, Jakarta: PT Gramedia Widia Sarana Indonesia.

Baehr, J. (2017). The Varieties of Character and Some Implications for Character Education. Journal of Youth and Adolescence, 46(6), 1153-1161. https://doi.org/10.1007/s10964-0170654-z

Buchanan, R. (2001). Problem of character in design education: liberal arts and professional specialization. International Journal of Technology and Design Education, 11(1), 13-26. https://doi.org/10.1023/A:1011286205 584

Chen, Y. L. (2013). A Missing Piece of the Contemporary Character Education Puzzle: The Individualisation of Moral Character. Studies in Philosophy and Education, 32(4), 345-360. https://doi.org/10.1007/s11217-0129331-6

Deny Setiawan. (2013). Peran Pendidikan Karakter dalam Mengembangkan Kecerdasan Moral. Jurnal Pendidikan Karakter, 1, 58.

Edwards III, George C. (1980). Implementing Public Policy. Washington D.C. Congressional Quarterly Inc.

Fajarini, U. (2014). Peranan Kearifan Lokal Dalam Pendidikan Karakter. SOSIO DIDAKTIKA: Social Science Education Journal, 1(2). https://doi.org/10.15408/sd.v1i2.1225

Faridatul Mardlotillah, "Implementasi Kebijakan Sekolah dalam Upaya Pengembangan Pendidikan Karakter melalui Program Pembiasaan Membaca Al-Qur'an" Jurnal Kebijakan dan Pengembangan Pendidikan (Juli, 2013) Vol 1, No. 2

Freeman, G. G. (2014). The Implementation of Character Education and Children's Literature to Teach Bullying Characteristics and Prevention Strategies to Preschool
Children: An Action Research Project. Early Childhood Education Journal, 42(5), 305-316. https://doi.org/10.1007/s10643-0130614-5

Gilead, T. (2011). Countering the Vices: On the Neglected Side of Character Education. Studies in Philosophy and Education, 30(3), 271-284. https://doi.org/10.1007/s11217-0119223-1

Hasan, S. H. (2012). Pendidikan Sejarah Untuk Memperkuat PeHasan, S. Hamid. 2012. "Pendidikan Sejarah Untuk Memperkuat Pendidikan Karakter." Paramita 22(1):8195.ndidikan Karakter. Paramita, 22(1), 81-95. https://doi.org/10.1109/JSTARS.2014. 2332337

Ismadi, H. D. (2014). Pendidikan Karakter dalam Prespektif Kebudayaan. 1(1), 3.

Jaya, H. (2012). Pengembangan Laboratorium Virtual Untuk Kegiatan Praktikum Dan Memfasilitasi Pendidikan Karakter Di Smk Virtual Laboratory Development for Practicum and Facilitating Character Education in Vocational High School. 10.

Khusniati, M. (2012). Jurnal Pendidikan IPA Indonesia PENDIDIKAN KARAKTER MELALUI PEMBELAJARAN IPA. Jpii, 1(2), 204-210. Retrieved from http://journal.unnes.ac.id/index.php/jpii

Lee, I.-J. (2001). The proper directions and practical ways for character education in the korean elementary school. Asia Pacific Education Review, 2(2), 7284. https://doi.org/10.1007/bf03026292

Miller, T. W., Kraus, R. F., \& Veltkamp, L. J. (2008). Character education as a prevention strategy for school-related violence. School Violence and Primary Prevention, 377-390. https://doi.org/10.1007/978-0-38777119-9_19 
Mulvey, C. (1984). Wage Policy and Wage Determination in 1983. Journal of Industrial Relations, 26(1), 112-119. https://doi.org/10.1177/002218568402 600108

Sujanto, Agus. (1996). Psikologi

Perkembangan, Rineka, Jakarta: Cipta.

Thelin, J. R. (2013). Success and Excess: The Contours and Character of American Higher Education Since
1960. Society, 50(2), 106-114.

https://doi.org/10.1007/s12115-0139630-8

Wening, S. (2012). The nation's character building through value education. Jurnal Pendidikan Karakter, 2(1), 5566. Retrieved from

http://journal.uny.ac.id/index.php/jpka/ article/view/1452 